\title{
A Review on the Potential of Natural Antioxidant Sources to Improve Oxidative Stability in Edible Oils
}

\author{
Tabligh Permana*, Nia Wiradjaja, Hery Sutanto, Vincent Satya Surya \\ Faculty of Life Sciences and Technology, Swiss German University, Tangerang, 15143, Indonesia \\ "Corresponding author. Email: tabligh.permana@gmail.com
}

\begin{abstract}
Edible oils have been used widely in food processing, especially processes with thermal treatment such as frying. In the frying process, oils are usually used repetitively and trigger the presence of lipid oxidation which results in the degradation of fatty acids. This degradation of fatty acids then results in the reduction of quality in oil which includes decreasing nutritional value. The reduction of quality in oil is very dangerous as it can migrate into the food that can be consumed by humans and trigger several negative health effects such as carcinogenic properties. In order to preserve the quality of the oil, antioxidants are used to improve its oxidative stability. As there are some restrictions and drawbacks of using synthetic antioxidants, natural antioxidants are more preferable to be used in the food industry. In this paper, the subjects that were reviewed are oils with high polyunsaturated fatty acids content and natural antioxidants that have the potential to improve oxidative stability of the oils which are rosemary extract, sesame seed extract, green tea extract and fruit peels extract. The optimum extraction method and active compounds contained in the extract also be discussed. The methodology of this paper is using journal reviews through Google Scholar. The keywords used to search related journals include natural antioxidant, antioxidant activity, rosemary extract, green tea extract, sesame seed extract, frying, heating, fatty acids, optimum extraction, edible oils, oxidative stability, lipid oxidation. Secondary data was obtained from other research which related to the changes of fatty acid composition after processing food with edible oils that have high unsaturated fatty acid content and analysis of several parameters for measuring oxidative stability. The usage of natural antioxidants which are rosemary extract, sesame seed extract, and green tea extract has been proven to improve oxidative stability of the oils and prevent degradation of polyunsaturated fatty acids. Polyphenolic compounds inside the extracts are the ones that contribute to its antioxidative activity. The optimum extraction method of the extracts is by using solvent extraction and the difference of solvent used is mainly based on the polarity of the extracts
\end{abstract}

Keywords: Active compound, Antioxidant activity, Edible oil, Fatty acids, Oxidative stability.

\section{INTRODUCTION}

Edible oils have been used widely in food industries and processing. Fatty acids content in edible oils are one of the major components that affect the oxidative stability. Oils that were oxidized can trigger the presence of lipid oxidation and other chemical reactions that can affect the quality of the final product which might be harmful to human health as it is a major source of destructive free radicals in human diets [1].

In lipid oxidation, reactive oxygen species (ROS) attack unsaturated fatty acids that contain multiple double bonds and methylene groups with hydrogen atoms and initiate the radical peroxidation chain reaction.
Antioxidants neutralize free radicals by accepting or donating electrons in order to eliminate the unpaired condition of the radical which leads to reacting with reactive radical and destroying them thus having the capability to inhibit oxidation. The addition of antioxidants to the edible oil have the potential to increase the oxidative stability of oil during different processing (heating and frying) and storage [2-6].

Natural antioxidants from plant extracts such as rosemary extracts, sesame seed extract, green tea extracts have already been proven to increase oxidative stability in edible oil during processing and storage. It also has comparable antioxidative activity as synthetic 
antioxidants and it also gives additional health benefits [2-6].

In this review, fatty acid compositions and stability of edible oil with high unsaturated fatty acid content used for deep frying will be discussed to achieve evidence of lipid oxidation. Due to the lipid oxidation occurred in edible oil used in food processing, the addition of several natural antioxidants including its active compounds that can improve the oxidative stability of edible oils will be discussed to prevent further oxidation in the oil and can preserve more unsaturated fatty acids inside the oil. The optimum extraction method of each extract will be discussed to achieve maximum extract yield and potential analysis regarding the review of several journals is also going to be discussed.

\section{MATERIALS AND METHOD}

This review paper with the title "A Review on The Potential of Natural Antioxidant Sources to Improve Oxidative Stability in Edible Oils" was conducted from April 2020 until June 2020 in Swiss German University.

The methodology of this paper is using journal reviews through Google Scholar which leads to Science Direct, Research Gate, Elsevier, Wiley, Semantic Scholar, National Center for Biotechnology Information and Link Springer.

The keywords used to search related journals include natural antioxidant, antioxidant activity, rosemary extract, green tea extract, sesame seed extract, frying, heating, fatty acids, optimum extraction, edible oils, oxidative stability, lipid oxidation.

Secondary data was obtained from other research which related to the changes of fatty acid composition after processing food with edible oils that have high unsaturated fatty acid content and analysis of several parameters for measuring oxidative stability.

\section{RESULTS AND DISCUSSION}

Sunflower oil has the most monounsaturated fatty acid content ( $\Sigma$ MUFA) which consist of $24 \%$ oleic acid compared to cottonseed oil and soybean oil. Edible oil with high MUFA content is known to be less prone to oxidation due to its fewer double bonds (Rauf et al., 2017). As for polyunsaturated fatty acids content, sunflower oil was also on the lead with the amount of $67.06 \%$ polyunsaturated fatty acids from total fatty acids in the oil which consist of linoleic acid and alphalinolenic acid.

\subsection{Fatty Acids Composition of Several Edible Oil After Deep-Frying}

Sharoba \& Ramadan [7] have done research about changes of fatty acid composition of an edible oil after deep frying process. The research used $3 \mathrm{~kg}$ each of sunflower oil and cottonseed oil as the frying medium with $300 \mathrm{~g}$ French fries per batch as the sample. The oil that was used was heated at $180^{\circ} \mathrm{C}$ and the samples were fried for 6 minutes at an interval of 10 minutes, for 16 hours.

After experiencing high heat temperature processing which is deep frying for sunflower oil, cottonseed oil and soybean oil, significant changes occurred in the fatty acid compositions.

\subsubsection{Changes of Polyunsaturated Fatty Acids (PUFAs) After Deep-Frying}

According to Figure 1, PUFAs content after deepfrying in sunflower oil $(y=-0.0056 x+65.7)$ appears to be more stable than cottonseed oil $(\mathrm{y}=-0.0232 \mathrm{x}+53.385)$ and soybean oil $(y=-0.0135 x+60.912)$. It might be affected by the physical properties of each oil, which is the smoke point where sunflower oil appears to have higher smoke points than the other oil [8].

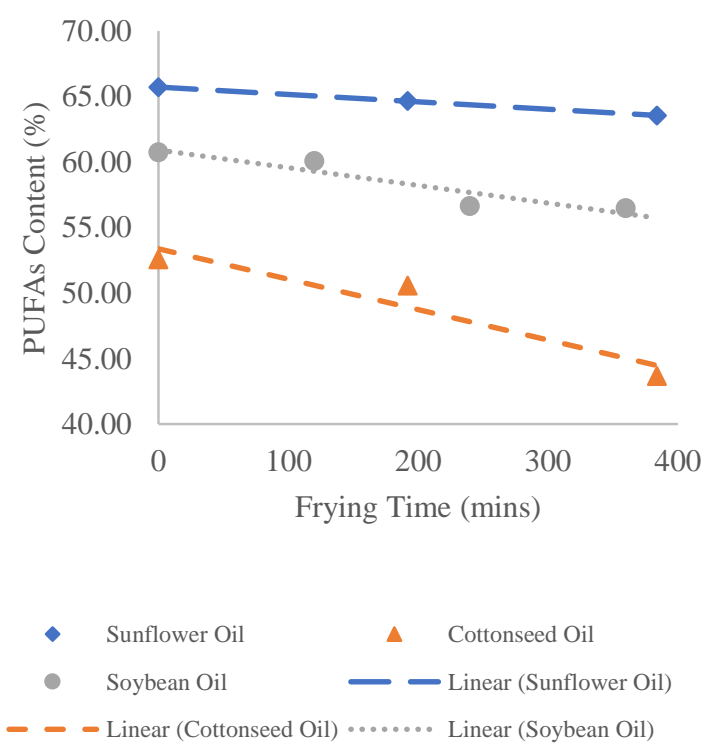

Figure 1. Changes in PUFAs Content in Sunflower, Cottonseed and Soybean Oils [7]

Another factor that might be affecting the stability of the oils is the amount of naturally occurring alphatocopherol contained in each oil where sunflower oil appears to contain the highest amount, followed by soybean oil [9]. Due to higher smoke point and alpha- 
tocopherol contained in sunflower oil, it appears to be more stable than the other oils.

The difference in the reduction value of each oil might be affected by the difference of frying time used in the experiment. It might also be affected by the sample difference where sunflower and cottonseed oil used French fries as the sample, while soybean oil used chicken as the sample. Naseri et al. [10] has done similar research about the changes of fatty acid compositions after frying silver carp (Hypophthalmichthys molitrix) by using sunflower oil, olive oil, corn oil and soybean oil. It was shown in the data that the total PUFAs in each oil decreased, while total PUFAs in silver carp increased.

According to Hakimeh et al. [11], the decrease of moisture inside the silver carp due to evaporation makes the fat contained in oil easier to come inside thus increasing fat content in silver carp. Therefore, the initial moisture inside the samples are also the factors of decreasing value of PUFAs content in the oil.

\subsubsection{Changes in Trans-Fat After Deep-Frying}

After the deep-frying process, it can also be seen that trans unsaturated fatty acids increase as the frying time increases in all samples as illustrated in Figure 2. It can happen due to the lack of stability of the cis configuration during oxidation process and changing it into trans configuration.
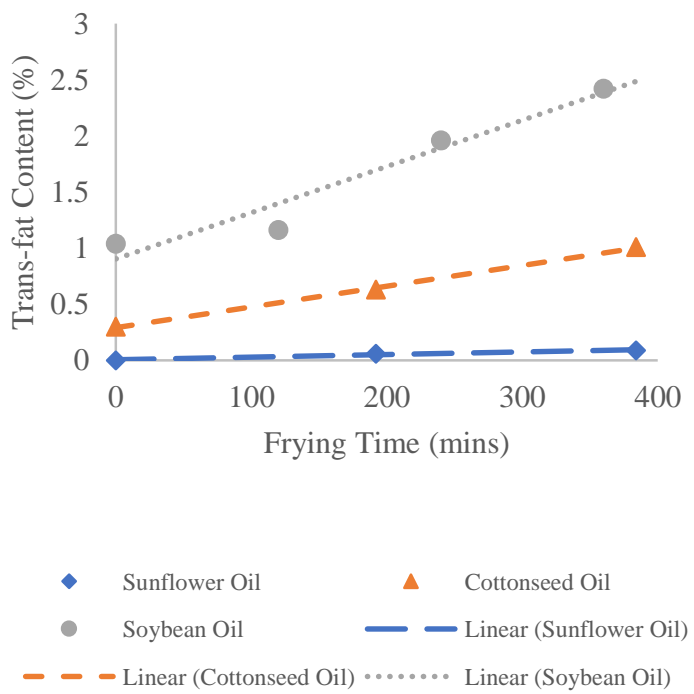

Figure 2. Changes in Transfat Content in Sunflower, Cottonseed and Soybean Oils [7]

This theory was supported by research from Bansal et al. [12] and Tsuzuki et al. [13] where the trans fatty acid of several edible oil also increased and cis fatty acids decreased prior to heating and frying treatment. This statement was also in line with the decreasing of PUFAs content in section 3.1.1 after deep frying where the cis configuration of PUFA decreased, thus increasing the trans-fat content.

When the oil is being heated, atoms occurred in cis configuration agitated and the hydrogen atom will be removed from the cis configuration and form lipid radical. Due to the removal of hydrogen atoms, the bond will become unstable, and it will quickly attract another hydrogen atom and it may attach to the other side of the chain, thus forming a trans configuration that will stabilize the fatty acids [14]. According to research by Moreno et al. [15], the significant increase of trans fatty acids in edible oils mostly started at $150^{\circ} \mathrm{C}$ and showed a continuous increase with the increase of time and temperature. However, trans fatty acid occurred during the research are considered as minor constituents as it does not occur in a high amount.

\subsubsection{Changes in Monounsaturated Fatty Acid (MUFA) after Deep-Frying}

After the deep-frying process, there are increasing values of $\mathrm{C} 18: 1$ cis known as oleic acid which is categorized as MUFA from the data. The increase of total MUFA in each oil after deep-frying was shown in Figure 3.
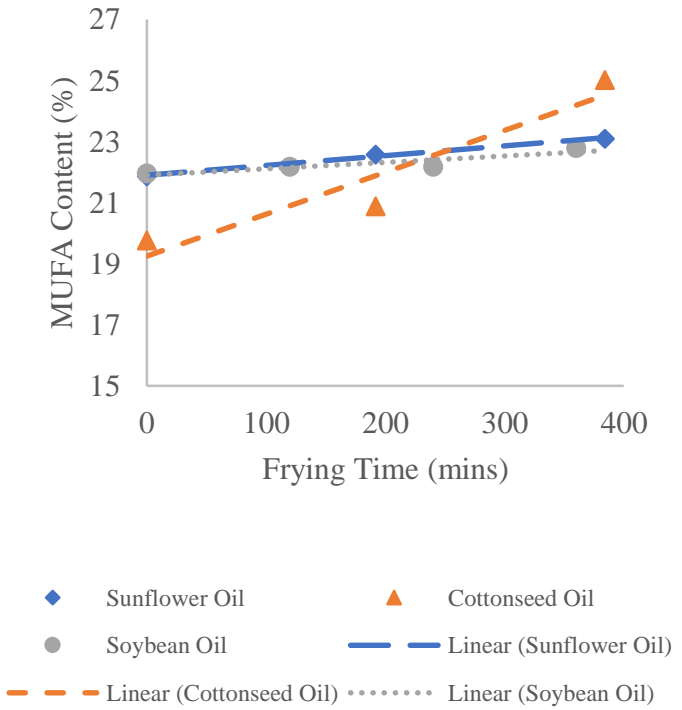

Figure 3. Changes in MUFA Content in Sunflower, Cottonseed and Soybean Oils [7]

From Figure 3, cottonseed oil experienced the highest increase of total MUFA with sunflower oil and soybean oil, respectively. Increase values of oleic acid might be caused by the migration of the fat contained in the samples to the oil and due to higher oxidative stability of MUFA $[7,10,16]$. Therefore, the differences in the 
increased percentage of monounsaturated fatty acids of each oil sample were also affected by the initial MUFA content in the sample.

Due to the instability of edible oils with high unsaturated fatty acid content that has been stated in section 3.1.1 and 3.1.2, the need to improve oxidative stability of those oils are essential. It is also important to note that the migration of fatty acids content from oil to food might be dangerous if the oil has been oxidized due to its capability of bringing undesirable chemical compound such as cytotoxic and genotoxic aldehydes which will affect the nutritional, physical and chemical properties of the food itself [17-18]

\subsection{Improvement of Oxidative Stability of Several Edible Oils by The Addition of Antioxidant}

There are two types of antioxidants used in edible oils which are natural antioxidant and synthetic antioxidant. Natural antioxidants have gained popularity due to the thoughts of consumers that natural ingredients are better than the synthetic ones [19]. Synthetic antioxidant has decreased in consumers interest due to its toxicity and carcinogenic properties and its limitation of use in several countries [20-23].

Natural antioxidant obtained from plant materials are mainly polyphenols (phenolic acids, anthocyanins, lignans and stilbenes), carotenoids (xanthophylls and carotenes) and vitamins (vitamin $\mathrm{C}$ and $\mathrm{E}$ ). As for the synthetic type of antioxidant, the most used are butylated hydroxytoluene (BHT), butylated hydroxyanisole (BHA) and tert butylhydroquinone (TBHQ) [24].

Most edible oils already contain natural antioxidants from its natural sources and it is called as tocopherol or known as Vitamin E. The level of tocopherol contained in the oil are important as it can contributes to its oxidative stability. The rosemary extract (Rosmarinus officinalis L.), sesame seed extract (Sesamum indicum), and green tea extract are the potential natural antioxidants in this case.

\subsubsection{The Addition of Rosemary Extract in Edible Oil}

It has been reported that the addition of rosemary extract in soybean oil that are heated at $180^{\circ} \mathrm{C}$ for 10 hours a day for two consecutive days improves its oxidative stability index and slows polyunsaturated fatty acid oxidation as shown in Figures 4 and 5. The addition of $3000 \mathrm{mg} / \mathrm{kg}$ rosemary extract also showed a comparable antioxidant activity on heated soybean oil as $50 \mathrm{mg} / \mathrm{kg}$ TBHQ and does not show synergistic effect between them. The concentration of TBHQ that is used is the most common concentration that is utilized by the soybean oil industry.

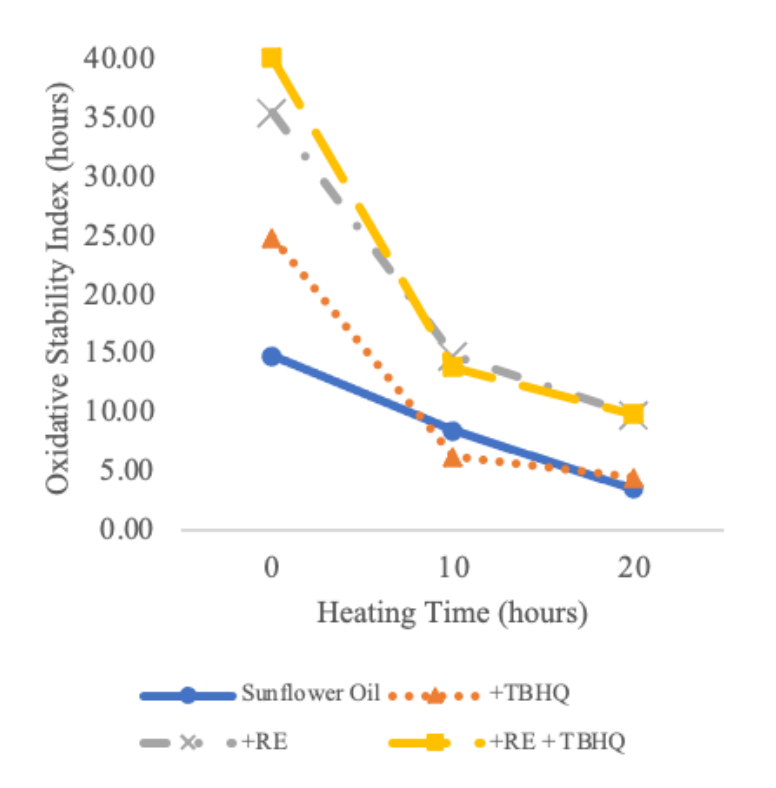

Figure 4 Changes of Oxidative Stability Index in Edible Oil with The Addition of Rosemary Extract

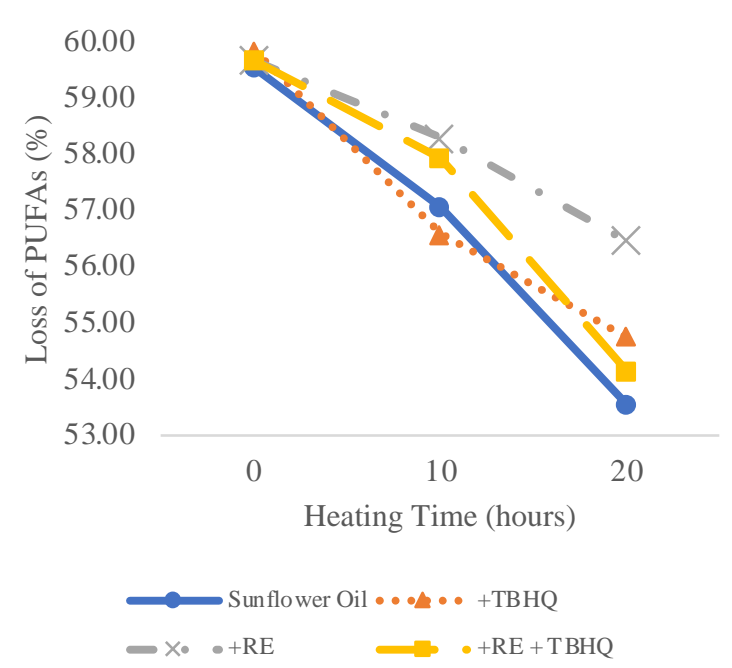

Figure 5 Changes of PUFAs Content in Edible Oil with The Addition of Rosemary Extract and TBHQ

Rosemary extract with the concentration of 400 $\mathrm{mg} / \mathrm{kg}$ also shows its capability as antioxidant in soybean and cottonseed oil which was stored in an oven at $62^{\circ} \mathrm{C}$ for 24 days where it slows down the formation of peroxide and shows a comparable activity with edible oils with the addition of 400 ppm BHA+BHT with 200 ppm each as shown in Figure 6 and 7 [5]. A 200 ppm is used as the concentration of BHA+BHT which is the usage limitation (BPOM, 2013; FDA, 2019).

When used in a deep-frying treatment of potato at $180^{\circ} \mathrm{C}$, sunflower oil with the addition of $1000 \mathrm{mg} / \mathrm{kg}$ rosemary extract was able to reduce the formation of free fatty acids and conjugated dienes even more than $50 \%$ if 
compared with BHA and control as shown in Figure 8 and $9[25]$.

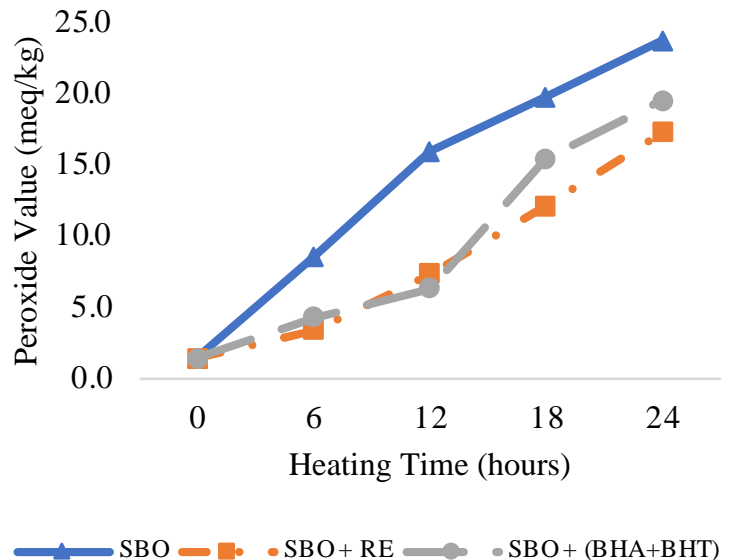

Figure 6 Changes of Peroxide Value in Soybean Oil with The Addition of Rosemary Extract and BHA+BHT [5]

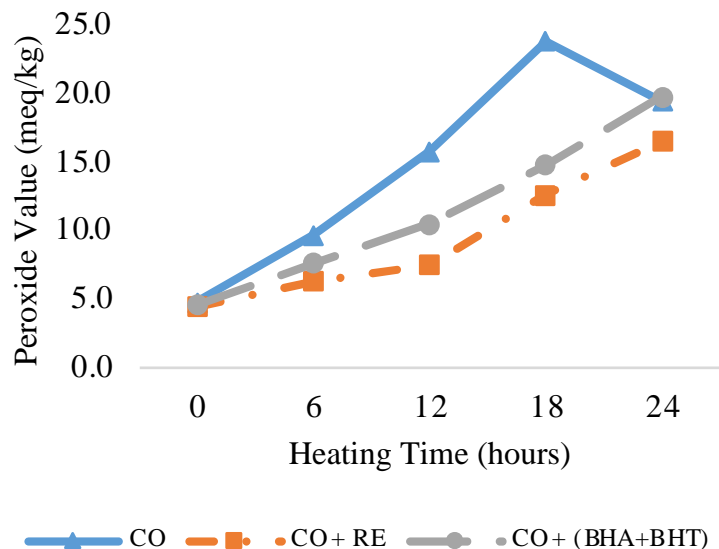

Figure 7 Changes of Peroxide Value in Cottonseed Oil with The Addition of Rosemary Extract and BHA+BHT [5]

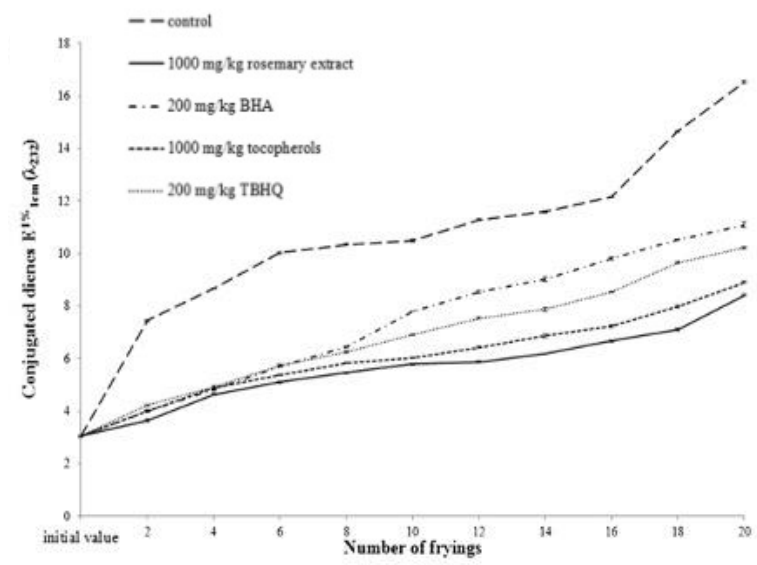

Figure 8 Changes of Conjugated Dienes Content in Sunflower Oil with The Addition of Rosemary Extract, BHA, Tocopherol and TBHQ [25]

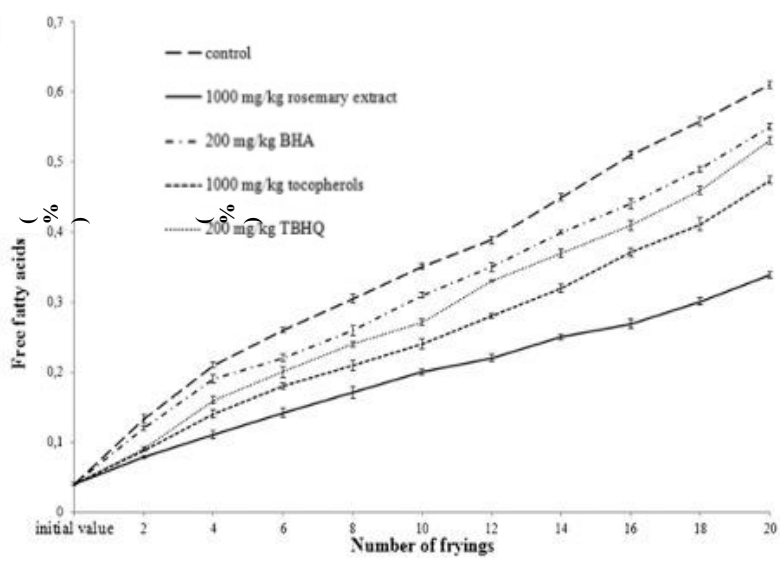

Figure 9 Changes of FFA Content in Sunflower Oil with The Addition of Rosemary Extract, BHA, Tocopherol and TBHQ [25]

Reduction of conjugated dienes after deep-frying process was correlated with its oxidative stability because it was both primary and secondary oxidation products which are produced from hydroperoxides. With the reducing values of both of them, it means that the oxidation process has become slower and produces less oxidation products which are caused by the increase of the oxidative stability of the oil.

From the studies, rosemary extract has the capability of becoming an antioxidant source in edible oil and comparable with synthetic antioxidants. Antioxidative properties of rosemary extract are correlated to its polyphenolic compounds. According to Mena et al. [26] there are 24 diterpenoids, 24 flavonoids and 5 phenolic acids in rosemary extract.

\subsubsection{The Addition of Sesame Seed Extract in Edible Oil}

Sesame seed extract has comparable antioxidant activity in sunflower and soybean oil that are store at $70^{\circ} \mathrm{C}$ in an oven with BHA, BHT and TBHQ by looking at the changes in the formation of conjugated dienes as shown in Figure 10 and 11 [4].

Sesamolin is thermally unstable and during thermal treatment, it was converted into sesaminol and sesamol which are the major antioxidant products in sesame seed extract [27-28]. It has been reported that both sesaminol and sesamol has high antioxidant activity which leads to its capability to retard peroxide value in oil and exhibit radical scavenging properties on DPPH. This oxidation product of sesamolin is the main reason for thermally stable and high oxidative stability of sesame seed extract [4]. Sesaminol also showed a synergistic effect with $\gamma$ tocopherol which is a natural antioxidant found in edible oils [29]. The synergistic effect of both antioxidants improved the oxidative stability of edible oil during thermal processing and storage [30]. 


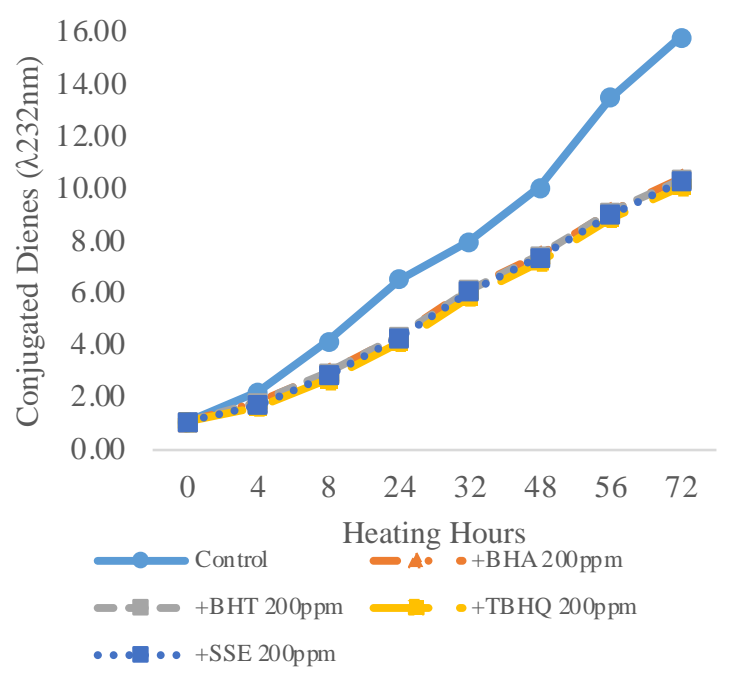

Figure 10 Changes of Conjugated Dienes in Soybean Oil with The Addition of Sesame Seed Extract, BHA, BHT and TBHQ [4]

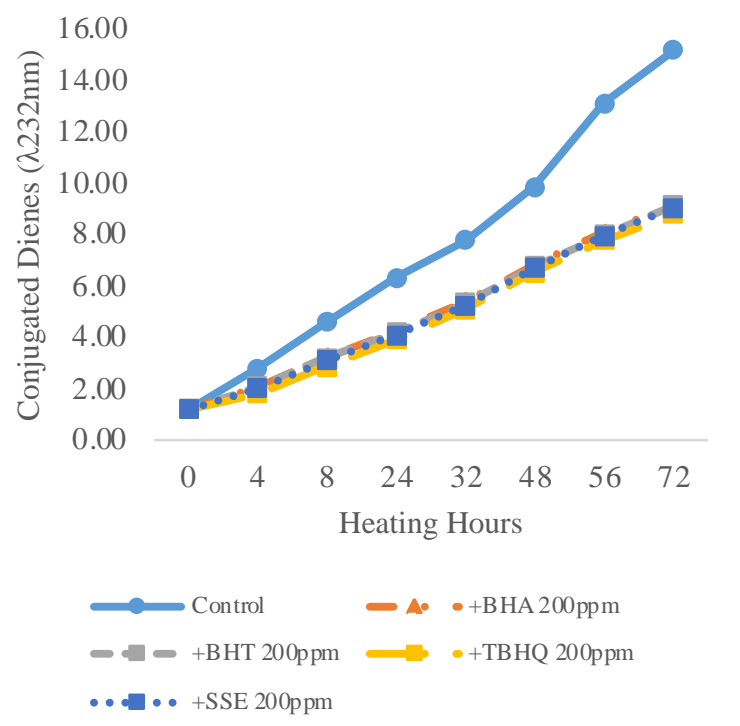

Figure 11 Changes of Conjugated Dienes in Sunflower Oil with The Addition of Sesame Seed Extract, BHA, BHT and TBHQ [4]

\subsubsection{The Addition of Green Tea Extract in Edible Oil}

In the addition of green tea extract in canola oil that was heated at $95^{\circ} \mathrm{C}$ for 98 hours, there is a decreasing value of reduction of polyunsaturated fatty acids after the heating period as shown in Figure 12.

Koketsu \& Satoh [3] has compared the use of several concentration of green tea extract (40 and $60 \mathrm{ppm}$ ) and $200 \mathrm{ppm}$ of tocopherol in soybean oil at $98^{\circ} \mathrm{C}$ for 30 hours. The result was shown in peroxide value where the addition of tocopherol does not show significant different with the control and green tea extract showed a significant lower peroxide value than control and tocopherol which is in line with another research [31] as shown in Figure 13. It is also shown that green tea extract was dose-dependent since the $60 \mathrm{ppm}$ concentration showed lower value than the $40 \mathrm{ppm}$ concentration. It is also reported that the peroxide value of oils used for frying noodles at $180^{\circ} \mathrm{C}$ are decreased with the addition of 40 and $60 \mathrm{ppm}$ green tea extract and $200 \mathrm{ppm}$ tocopherol, with lower value in green tea extracts [3].

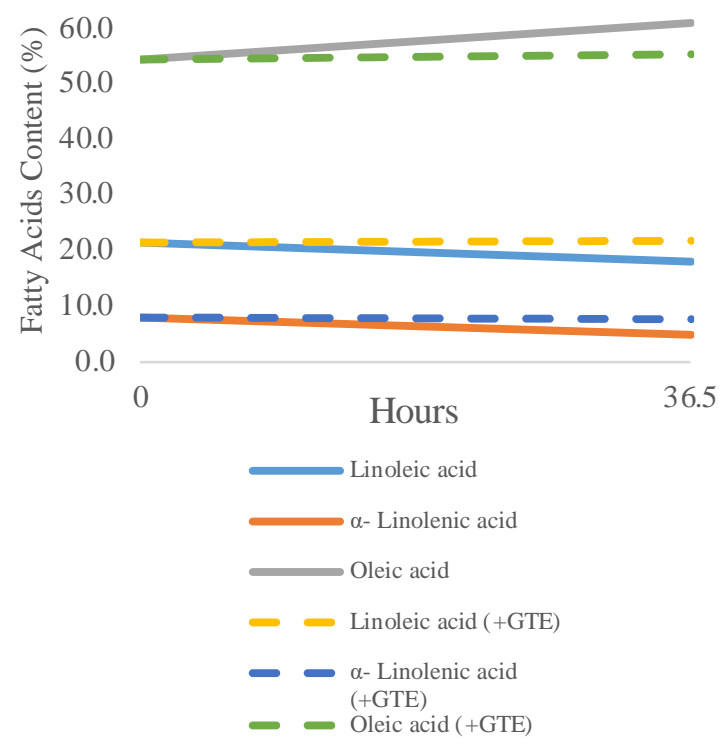

Figure 12 Changes of Fatty Acids Content in Edible Oil with The Addition of Green Tea Extract [2]

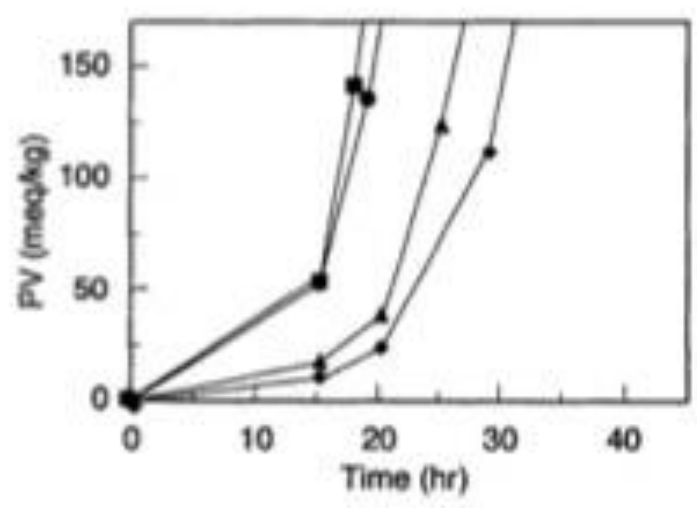

Figure 13 Changes of Peroxide Value in Edible Oil with The Addition of Green Tea Extract and Tocopherol [3]

Antioxidant properties of green tea extract are related to its high phenolic content. The major compound that contributes to green tea antioxidant properties are catechins that make up to $25-35 \%$ of the dry weight of green tea leaves [32]. The four major catechins are epigallocatechin-gallate (EGCG), epicatechin-gallate (ECG), epigallocatechin (EGC) and epicatechin (EC) 
with the range percentage found are 27.4-59.0\%, 7.9$13.6 \%, 19.0-34.23 \%$ and $6.4-16.14 \%$ of total catechins, respectively [33-34]. The difference of individual compound percentage found in green tea might be due to the difference of methods and green tea variety that are used. It has also been reported that the concentration of catechins in green tea is 35 times higher than black tea which makes it more suitable as an antioxidant source rather than black tea.

\subsection{Potential Analysis}

All the extracts that have been reviewed show its capability to improve oxidative stability in all the edible oils that have been examined. From the references, the addition of natural extracts as antioxidant source in edible oil does not depend on the type of oils that are used, as there is no difference in the result of the parameter of oxidative stability.

From the bioactive compound structure of the extracts, rosemary and sesame seed might be potential for high temperature processing. Rosemary extract contains carnosic acid which when exposed to heat, it can still remain as an antioxidant product which is carnosol. As for sesame seed extract, it has sesamolin which can also be converted into sesaminol and sesamol when exposed to heat and provide the antioxidant effect.

Table 1. Potential Temperature of Each Extracts to Improve Oxidative Stability

\begin{tabular}{cc}
\hline Extracts & Temperature \\
\hline Rosemary Extract & $62^{\circ} \mathrm{C} \& 180^{\circ} \mathrm{C}$ \\
\hline Sesame Seed Extract & $25^{\circ} \mathrm{C} \mathrm{\&} 72^{\circ} \mathrm{C}$ \\
\hline Green Tea Extract & $95^{\circ} \mathrm{C}-98^{\circ} \mathrm{C}$ \\
\hline
\end{tabular}

It is hard to come to a conclusion regarding the most potential extracts due to the differentiation of methods that are used. However, from the data provided in several journals, the natural extracts have shown its potential to improve oxidative stability in certain temperatures as shown in Table 1. Only rosemary extract that has been proven to increase oxidative stability in edible oil during frying temperature, which commonly in the range of $160^{\circ} \mathrm{C}$ to $180^{\circ} \mathrm{C}$. However, all other extract also has the potential to improve oxidative stability in edible oil during processing and storage below $100^{\circ} \mathrm{C}$.

\section{CONCLUSION}

Edible oils that are exposed to heat or not stored properly experienced several chemical reactions which lead to the degradation of polyunsaturated fatty acids due to its low oxidative stability. The usage of natural antioxidants which are rosemary extract, sesame seed extract, and green tea extract has been proven to improve oxidative stability of the oils and prevent degradation of polyunsaturated fatty acids. Polyphenolic compounds inside the extracts are the ones that contribute to its antioxidative activity. The optimum extraction method of the extracts is by using solvent extraction and the difference of solvent used is mainly based on the polarity of the extracts.

Rosemary extract has the potential to improve oxidative stability in edible oils used for frying $\left(>160^{\circ} \mathrm{C}\right)$, while green tea and sesame seed, have the potentials for treatment below $100^{\circ} \mathrm{C}$.

\section{REFERENCES}

[1] Choe, E., \& Min, D. B. (2007). Chemistry of deepfat frying oils. Journal of Food Science, 72(5). https://doi.org/10.1111/j.1750-3841.2007.00352.x

[2] Chen, Z. Y., \& Chan, P. T. (1996). Antioxidative activity of green tea catechins in canola oil. Chemistry and Physics of Lipids, 82(2), 163-172. https://doi.org/10.1016/0009-3084(96)02587-X

[3] Koketsu, M., \& Satoh, Y. I. (1997). Antioxidative activity of green tea polyphenols in edible oils. Journal of Food Lipids, 4(1), 1-9. https://doi.org/10.1111/j.1745$\underline{\text { 4522.1997.tb00076.x }}$

[4] Mohdaly, A. A. A., Smetanska, I., Ramadan, M. F., Sarhan, M. A., \& Mahmoud, A. (2011). Antioxidant potential of sesame (Sesamum indicum) cake extract in stabilization of sunflower and soybean oils. Industrial Crops and Products, 34(1), 952-959. https://doi.org/10.1016/j.indcrop.2011.02.018

[5] Yang, Y., Song, X., Sui, X., Qi, B., Wang, Z., Li, Y., \& Jiang, L. (2016). Rosemary extract can be used as a synthetic antioxidant to improve vegetable oil oxidative stability. Industrial Crops and Products, 80 ,

141-147. https://doi.org/10.1016/j.indcrop.2015.11.044

[6] Hussain, S. A., Hameed, A., Ajmal, I., Nosheen, S., Suleria, H. A. R., \& Song, Y. (2018). Effects of sesame seed extract as a natural antioxidant on the oxidative stability of sunflower oil. Journal of Food Science and Technology, 55(10), 4099-4110. https://doi.org/10.1007/s13197-018-3336-2

[7] M. Sharoba, A., \& Ramadan, M. F. (2017). Impact of Frying on Fatty Acid Profile and Rheological Behaviour of Some Vegetable Oils. Journal of Food Processing \& Technology, 03(07). https://doi.org/10.4172/2157-7110.1000161

[8] Coro, K. D. (2020, February 25). What is the smoke point of your cooking oil and why does it matter? Retrieved June 5, 2020, from https://www.verywellfit.com/smoke-points-ofcooking-oils-4781972

[9] Desai, I. D., Bhagavan, H., Salkeld, R., \& Dutra de Oliveira, J. E. (1988). Vitamin E content of crude and refined vegetable oils in Southern Brazil. Journal of Food Composition and Analysis, 1(3), 
$231-238$. 1575(88)90004-X

https://doi.org/10.1016/0889-

[10] Naseri, M., Abedi, E., Mohammadzadeh, B., \& Afsharnaderi, A. (2013). Effect of frying in different culinary fats on the fatty acid composition of silver carp. Food Science \& Nutrition, 1(4), 292-297. https://doi.org/10.1002/fsn3.40

[11] Hakimeh, J. A., Akram, A. A., Bahareh, S., \& Alireza, S. M. (2010). Physicochemical and sensory properties of silver carp (Hypophthalmichthys molitrix) fillets as affected by cooking methods. International Food Research Journal, 17(4), 921926

[12] Bansal, G., Zhou, W., Tan, T. W., Neo, F. L., \& Lo, H. L. (2009). Analysis of trans fatty acids in deep frying oils by three different approaches. Food Chemistry, 116(2), 535-541. https://doi.org/10.1016/j.foodchem.2009.02.083

[13] Tsuzuki, W., Matsuoka, A., \& Ushida, K. (2010). Formation of trans fatty acids in edible oils during the frying and heating process. Food Chemistry, 123(4), 976-982. https://doi.org/10.1016/j.foodchem.2010.05.048

[14] Malczewski, P. (2017, September 29). Triglycerides - basic chemistry. Retrieved June 5, 2020, from https://www.nutritionmyths.com/triglyceridesbasic-chemistry/\#transfattyacids

[15] Moya Moreno, M. C. M., Mendoza Olivares, D., Amézquita López, F. J., Gimeno Adelantado, J. V., \& Bosch Reig, F. (1999). Determination of unsaturation grade and trans isomers generated during thermal oxidation of edible oils and fats by FTIR. Journal of Molecular Structure, 482483(May), 551-556. https://doi.org/10.1016/S00222860(98)00937-5

[16] Romero, A., Cuesta, C., \& Sánchez-Muniz, F. J. (1998). Effect of oil replenishment during deep-fat frying of frozen foods in sunflower oil and higholeic acid sunflower oil. JAOCS, Journal of the American Oil Chemists' Society, 75(2), 161-167. https://doi.org/10.1007/s11746-998-0028-5

[17] Moumtaz, S., Percival, B. C., Parmar, D., Grootveld, K. L., Jansson, P., \& Grootveld, M. (2019). Toxic aldehyde generation in and food uptake from culinary oils during frying practices: peroxidative resistance of a monounsaturate-rich algae oil. Scientific Reports, 9(1), 1-21. https://doi.org/10.1038/s41598-019-39767-1

[18] Feng, S., \& Wang, Y. (2020). Toxicity and Safety of Fats and Oils. Bailey's Industrial Oil and Fat Products, $1-16$. https://doi.org/10.1002/047167849x.bio059.pub2

[19] Yanishlieva, N. V., \& Marinova, E. M. (2001). Stabilisation of edible oils with natural antioxidants. European Journal of Lipid Science and Technology, 103(11), 752-767. https://doi.org/10.1002/14389312(200111)103:11<752::AIDEJLT752>3.0.CO; $\underline{2-0}$
[20] Hui, H. Y. 2006. Handbook of Food Science, Technology and Engineering Volume 4. NW, USA.

[21] Poiana, M. A. (2012). Enhancing oxidative stability of sunflower oil during convective and microwave heating using grape seed extract. International Journal of Molecular Sciences, 13(7), 9240-9259. https://doi.org/10.3390/ijms13079240

[22] Atta, E. M., Moha Malczewski, P. (2017, September 29). Triglycerides - basic chemistry. Retrieved June 5, 2020, from https://www.nutritionmyths.com/triglyceridesbasic-chemistry/\#transfattyacidsmed, N. H., \& Abdelgawad, A. A. M. (2017). Antioxidants: An Overview on the Natural and Synthetic Types. European Chemical Bulletin, 6(8), 365. https://doi.org/10.17628/ecb.2017.6.374-384

[23] Center for Food Safety and Applied Nutrition. (2014). Food Additives \& Ingredients - Food Additive Status List. 1-70. Retrieved from http://www.fda.gov/food/ingredientspackaginglabel ing/foodadditivesingredients/ucm091048.htm

[24] Taghvaei, M., \& Jafari, S. M. (2015). Application and stability of natural antioxidants in edible oils in order to substitute synthetic additives. Journal of Food Science and Technology, 52(3), 1272-1282. https://doi.org/10.1007/s13197-013-1080-1

[25] Urbančič, S., Kolar, M. H., Dimitrijević, D., Demšar, L., \& Vidrih, R. (2014). Stabilisation of sunflower oil and reduction of acrylamide formation of potato with rosemary extract during deep-fat frying. LWT - Food Science and Technology, 57(2), 671-678. https://doi.org/10.1016/j.lwt.2013.11.002

[26] Mena, P., Cirlini, M., Tassotti, M., Herrlinger, K. A., Dall'Asta, C., \& Del Rio, D. (2016). Phytochemical profiling of flavonoids, phenolic acids, terpenoids, and volatile fraction of a rosemary (Rosmarinus officinalis L.) extract. Molecules, 21(11), 1-15. https://doi.org/10.3390/molecules21111576

[27] Fukuda, Y., Nagata, M., Osawa, T., \& Namiki, M. (1986). Contribution of lignan analogues to antioxidative activity of refined unroasted sesame seed oil. Journal of the American Oil Chemists' Society, 63(8), 1027-1031. https://doi.org/10.1007/BF02673792

[28] Suja, K. P., Jayalekshmy, A., \& Arumughan, C. (2005). Antioxidant activity of sesame cake extract. Food Chemistry, 91(2), 213-219. https://doi.org/10.1016/j.foodchem.2003.09.001

[29] Dachtler, M., Van De Put, F. H. M., Stijn, F. V., Beindorff, C. M., \& Fritsche, J. (2003). On-line LCNMR-MS characterization of sesame oil extracts and assessment of their antioxidant activity. European Journal of Lipid Science and Technology, 105(9), 488-496. https://doi.org/10.1002/ejlt.200300835

[30] Yoshida, H., \& Takagi, S. (1999). Antioxidative effects of sesamol and tocopherols at various concentrations in oils during microwave heating. 
Journal of the Science of Food and Agriculture, $79(2)$, 220-226.

https://doi.org/10.1002/(SICI)1097-

0010(199902)79:2<220::AID-JSFA173>3.0.CO;2$\underline{8}$

[31] Jung, L., Lee, E., \& Choe, E. (2014). Effects of catechin and $\alpha$-tocopherol addition on the autoxidative stability of diacylglycerol oil derived from an olive oil and perilla oil mixture. Food Science and Biotechnology, 23(6), 1793-1798. https://doi.org/10.1007/s10068-014-0245-7

[32] Namal Senanayake, S. P. J. (2013). Green tea extract: Chemistry, antioxidant properties and food applications - A review. Journal of Functional Foods, 5(4), 1529-1541. https://doi.org/10.1016/j.jff.2013.08.011

[33] Cabrera, C., Artacho, R., \& Giménez, R. (2006). Beneficial Effects of Green Tea-A Review. Journal of the American College of Nutrition, 25(2), 79-99.

https://doi.org/10.1080/07315724.2006.10719518

[34] Komes, D., Horžić, D., Belščak, A., Ganić, K. K., \& Vulić, I. (2010). Green tea preparation and its influence on the content of bioactive compounds. Food Research International, 43(1), 167-176. https://doi.org/10.1016/j.foodres.2009.09.022 